\title{
УСТОЙЧИВОСТЬ КАРБАПЕНЕМРЕЗИСТЕНТНЫХ ШТАММОВ КLEВSIELLA PNEUMONIAE К КОЛИСТИНУ: МОЛЕКУЛЯРНЫЕ МЕХАНИЗМЫ И БАКТЕРИАЛЬНЫЙ ФИТНЕС
}

О. В. Шамина' ${ }^{\natural}$, О. А. Крыжановская', А. В. Лазарева', Н. М. Алябьева', Н. А. Маянский²

Национальный медицинский исследовательский центр здоровья детей, Москва, Россия

2 Российский национальный исследовательский медицинский университет имени Н. И. Пирогова, Москва, Россия

\begin{abstract}
В последние годы широкое использование колистина в лечении инфекционных заболеваний привело к появлению и распространению колистинрезистентности. По данным литературы, формирование устойчивости может приводить к затратам внутренних биологических ресурсов и снижению уровня приспособленности и поддержания жизнедеятельности (бактериального фитнеса). Целью исследования было изучить молекулярные механизмы резистентности к колистину и их влияние на бактериальный фитнес карбапенемрезистентных (карба-Р) штаммов К. рпеитопіае, выделенных у пациентов в г. Москве в 2012-2017 гг. Из 159 карба-Р-изолятов 71 изолят (45\%) обладал резистентностью к колистину (минимальная подавляющая концентрация больше 2 мг/л); секвенирование по методу Сенгера позволило обнаружить механизмы устойчивости у 26 (37\%) изолятов. Кривые роста были построены путем измерения оптической плотности при длине волны 600 нм в течение 15 ч. Конкурентный рост колистинрезистентных (кол-Р) изолятов K. pneumoniae оценивали относительно колистинчувствительного (кол-Ч) изолята. Кол-Р- и кол-Ч-изоляты в экспоненциальной фазе роста смешивали в пропорции 1 : 1, инкубировали в среде Луриа-Бертани и затем наносили на агар Луриа-Бертани, содержащий 10 мг/л колистина, и без него. Индекс конкуренции рассчитывали как отношение выросших кол-Р- и кол-Ч-колоний. Резистентность к колистину не влияла на кинетику роста K. pneumoniae, но снижала конкурентоспособность относительно кол-Ч-изолята. Тем не менее были обнаружены кол-Р-изоляты с высоким уровнем конкурентоспособности по сравнению с кол-Ч-изолятами такого же сиквенс-типа. Таким образом, необходимы дальнейшие исследования влияния резистентности к колистину на бактериальный фитнес.
\end{abstract}

Ключевые слова: Klebsiella pneumoniae, бактериальный фитнес, колистинрезистентность, mgrB, сиквенс-тип

Финансирование: исследование выполнено при поддержке гранта Российского научного фонда (проект № 20-15-00235).

Благодарности: авторы благодарят С. В. Поликарпову из Городской клинической больницы № 15 имени О. М. Филатова и О. В. Карасеву из Научноисследовательского института неотложной детской хирургии и травматологии за предоставление изолятов K. pneuтопіае.

Вклад авторов: О. В. Шамина - планирование и проведение исследования, анализ литературы, сбор, анализ и интерпретация данных, подготовка текста публикации; О. А. Крыжановская, А. В. Лазарева, Н. М. Алябьева - планирование и проведение исследования; Н. А. Маянский - научное руководство, планирование и проведение исследования, анализ литературы, сбор, анализ и интерпретация данных, подготовка и редактирование рукописи.

Соблюдение этических стандартов: исследование было проведено с соблюдением всех правил безопасности работы с микроорганизмами III-IV групп патогенности.

$\bigotimes$ Для корреспонденции: Ольга Вячеславовна Шамина

Ломоносовский проспект, д. 2, стр. 1, г. Москва, 119991; olga.shamina@inbox.ru

Статья получена: 18.05.2020 Статья принята к печати: 02.06.2020 Опубликована онлайн: 12.06.2020

DOI: $10.24075 /$ vrgmu.2020.032

\section{COLISTIN RESISTANCE OF CARBAPENEM-RESISTANT KLEBSIELLA PNEUMONIAE STRAINS: MOLECULAR MECHANISMS AND BACTERIAL FITNESS}

Shamina $\mathrm{OV}^{1} \otimes$, Kryzhanovskaya $\mathrm{OA}^{1}$, Lazareva $\mathrm{AV}^{1}$, Alyabieva NM¹, Mayanskiy NA²

${ }^{1}$ National Medical Research Center for Children's Health, Moscow, Russia

2 Pirogov Russian National Research Medical University, Moscow, Russia

\begin{abstract}
The increasing use of colistin in the clinic has led to the emergence and spread of colistin resistance. According to the literature, antibiotic resistance can have a metabolic cost, resulting in poor adaptation and survival, i.e. reduced bacterial fitness. The aim of this study was to investigate molecular mechanisms underlying resistance to colistin and their effect on the bacterial fitness of carbapenem-resistant (carba-R) strains of $K$. pneumoniae isolated from the patients of Moscow hospitals in 2012-2017. Of 159 analyzed carba-R isolates, 71 (45\%) were resistant to colistin (minimum inhibitory concentration over 2 mg/L). By conducting Sanger sequencing, we were able to identify the mechanisms underlying colistin resistance in 26 (37\%) isolates. Growth curves were constructed by measuring optical density at $600 \mathrm{~nm}$ wavelength for 15 hours. The competitive growth of colistin-resistant (col-R) K. pneumoniae isolates was assessed relative to the colistinsusceptible (col-S) isolate. Col-R and col-S cultures harvested in the exponential phase were combined at the ratio of 1:1, incubated in the Luria-Bertani medium and plated onto Luria-Bertani agar plates with $10 \mathrm{mg} / \mathrm{L}$ colistin and without it. The competition index was calculated as the ratio of grown col-R and col-S colonies. Resistance to colistin did not affect the growth kinetics of $K$. pneumoniae, but did reduce the competitive ability of the bacteria as compared to the col-S isolates. However, some col-R isolates were more competitive than the col-S strains of the same sequence type. Further research is needed to elucidate the effects of colistin resistance on bacterial fitness.
\end{abstract}

Keywords: Klebsiella pneumoniae, bacterial fitness, colistin resistance, $m g r B$, sequence type

Funding: the study was supported by the Russian Science Foundation (Project ID 20-15-00235).

Acknowledgements: the authors thank Polikarpova SV of Filatov City Clinical Hospital № 15 and Karaseva OV of the Research Institute of Emergency Pediatric Surgery and Traumatology for K. pneumoniae isolates.

Author contribution: Shamina OV planned and conducted the study, analyzed the literature, analyzed and interpreted the obtained data, and wrote the manuscript; Kryzhanovskaya OA, Lazareva AV, Alyabieva NM planned and conducted the study; Mayanskiy NA planned, conducted and supervised the study, analyzed the literature, collected, analyzed and interpreted the obtained data, and wrote the manuscript.

Compliance with ethical standards: the study was carried out following the safety guidelines on the manipulations with pathogens of hazard groups III and IV

$\bowtie$ Correspondence should be addressed: Olga V. Shamina

Lomonosovskiy prospect, 2, str. 1, Moscow, 119991; olga.shamina@inbox.ru

Received: 18.05.2020 Accepted: 02.06.2020 Published online: 12.06.2020

DOI: $10.24075 /$ brsmu.2020.032 
Klebsiella pneumoniae - одна из наиболее частых причин заболеваний, требующих оказания медицинской помощи [1]. Особую обеспокоенность вызывают появление и глобальное распространение отдельных сиквенс-типов K. pneumoniae высокого риска, которые обладают множественной лекарственной устойчивостью (МЛУ) [2, 3]. В первую очередь это относится к карбапенемрезистентным (карба-Р) K. pneumoniae, поскольку устойчивость к карбапенемам в большинстве случаев сочетается с резистентностью к другим антимикробным препаратам, что существенно ограничивает возможности терапии. Согласно данным мультилокусного сиквенс-типирования (МЛСТ), большинство карба-Р-изолятов принадлежит к узкому ряду сиквенс-типов, доминирующих в структуре госпитальных популяций повсеместно [4, 5]. В настоящее время к числу глобально диссеминированных относят МЛУ-сиквенс-типы ST14/15, ST17/20, ST43, ST147, ST258, ST395 [5, 6], а также ST307, который приобрел значимость сравнительно недавно [7].

Одним из препаратов, сохраняющих активность в отношении карба-Р грамотрицательных организмов, является поликатионный антибиотик колистин (полимиксин Е). Возросшее использование колистина в клинике на фоне распространения устойчивости к карбапенемам привело к появлению колистинрезистентности [4, 8], которая может существенно снижать эффективность антимикробной терапии и проявляться увеличением показателей смертности инсицированных колистинрезистентными (кол-Р) K. pneumoniae [9].

Устойчивость к колистину обусловлена модификацией липополисахарида (ЛПС), например, путем изменения его структуры, что снижает связывание антибиотика с клеточной стенкой бактерии [10]. Модификация ЛПС связана с повреждением двухкомпонентной системы PhoPQ/PmrAB и ее регулятора MgrB в результате мутаций

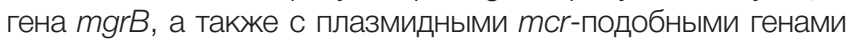
$[8,10]$.

Мутации, приводящие к развитию устойчивости, дают бактериям преимущество перед чувствительными штаммами в присутствии антибиотика, однако формирование и поддержание резистентности могут быть сопряжены с определенными биологическими затратами. Последние могут быть выражены в снижении темпов роста и уменьшении конкурентоспособности (т. е. уровня поддержания жизнедеятельности, который обозначают термином «бактериальный фитнес») [11, 12] по сравнению с чувствительными штаммами в отсутствие селективного действия антибиотика $[13,14]$. С учетом того, что устойчивость к колистину связана с модификацией важнейшего компонента клеточной стенки бактерий ЛПС, колистинрезистентность может быть сопряжена со снижением бактериального фитнеса.

Целью работы было охарактеризовать генотипы карба-Р-изолятов K. pneumoniae, выделенных у пациентов хирургических отделений и отделений реанимации и интенсивной терапии (ОРИТ) в г. Москве, и описать молекулярные механизмы устойчивости к колистину, а также исследовать влияние колистинрезистентности на кинетику роста и конкурентоспособность этой популяции бактерий.

\section{МАТЕРИАЛЫ И МЕТОДЫ}

Исследовали 159 карба-Р-изолятов K. pneumoniae (минимальная подавляющая концентрация (МПК) меропенема больше 8 мг/л и МПК имипенема больше 4 мг/л, согласно критериям EUCAST) [15], чувствительные и резистентные к колистину, собранные в течение 2012-2017 гг. в г. Москве от пациентов хирургических отделений и ОРИТ. В коллекцию были включены только недублирующиеся изоляты, т. е. от одного пациента - один изолят K. pneumoniae, включая изоляты из стерильных локусов (кровь, моча, ликвор), из респираторного тракта (аспират, мокрота), стомы, раны, зева, ануса.

МПК к меропенему, имипенему и тигециклину определяли с помощью метода Е-тестов (BioMerieux; Франция) на среде Мюллера-Хинтона (Bio Rad; Франция). Чувствительность к аминогликозидам (гентамицину, нетилмицину, амикацину), ципрофлоксацину, фоссромицину, цефотаксиму, цесепиму, цефтазидиму оценивали на автоматизированном бактериологическом анализаторе VITEK 2 Compact (BioMerieux; Франция). Субстанцию колистина в форме порошка (Sigma Aldrich; Германия) использовали для определения МПК колистина с помощью метода микроразведений в соответствии с Национальным стандартом Российской Федерации (ГОСТ Р ИСО 20776-12010). В качестве контроля использовали штамм Escherichia coli ATCC 25922. Согласно критериям EUCAST [15], пограничные значения МПК колистина для K. pneumoniae составляют: чувствительные $\leq 2$ мг/л, резистентные $>2$ мг/л.

Выявление и/или секвенирование по методу Сенгера генов $m c r-1$, mgrB, pmrA, pmrB, phoP и phoQ, исследование аминокислотных последовательностей белков PmrA, PmrB, PhoP и PhoQ проводили согласно ранее описанным процедурам [16]. В качестве контроля выявления гена $\mathrm{mcr}-1$ использовали mcr-1-положительный штамм E. coli (штамм предоставил НИИ антимикробной химиотерапии ФГБОУ ВО СГМУ Минздрава России). Для генотипирования штаммов K. pneumoniae использовали метод МЛСТ [17]. Идентификацию вставочных элементов проводили с помощью базы данных ISfinder [18].

Для исследования бактериального фитнеса были отобраны колистинчувствительные (кол-Ч) изоляты и колистинрезистентные (кол-Р) изоляты с поврежденными mgrB и mgrB дикого типа. Использовали суточные культуры K. pneumoniae, выращенные на агаре ЛуриаБертани, или LB (HiMedia Laboratories Pvt. Limited; Индия), согласно ранее описанным протоколам исследования бактериального фритнеса [14]. Готовили взвесь из одной колонии в среде LB и инкубировали в орбитальном шейкере-инкубаторе ES-20 (BioSan; Латвия) при $37^{\circ} \mathrm{C}$ в течение 3 ч при постоянном перемешивании 250 об./мин. Концентрацию микроорганизмов измеряли на проточном цитометре Novocyte (ACEA Biosciences; CШA).

Для сравнительного анализа кривых роста кол-Ч- и кол-Р-бактерий суспензию доводили до концентрации бактериальных клеток $5 \times 10^{6}$ в 1 мл. Полученную бактериальную взвесь в объеме 250 мкл инкубировали в 96-луночных плоскодонных планшетах в трех повторах для каждого штамма в присутствии колистина в концентрации 0, 1, 4, 16, 64 мг/л. Инкубацию проводили в многофункциональном микропланшетном ридере Infinite 200 (Tеcan; Австрия) в течение 15 ч при $37^{\circ} \mathrm{C}$ с параллельной оценкой оптической плотности при длине волны 600 нм $\left(О П_{600}\right)$ каждые 30 мин. Данные регистрировали при помощи программы Magellan 6.6 (Tecan; Австрия). В качестве индикатора интенсивности роста использовали значение площади под кривой роста (ПКР), которую рассчитывали от начала экспоненциального роста до выхода кривой на плато (рис. 1) и выражали в ОП 600 за 14. 
Для оценки конкурентоспособности кол-Р- и кол-Чизолятов K. pneumoniae рассчитывали индекс конкуренции (ИК). Для этого суспензию кол-Р- и кол-Ч-изолятов доводили до концентрации 1,5 × 103 в 1 мл и смешивали в соотношении $1: 1$ (1,5 × 103 в 1 мл KOE каждого штамма). Смесь кол-Р- и кол-Ч-изолятов, а также суспензии кол-Ри кол-Ч- изолятов по отдельности выращивали в среде LB при $37^{\circ} \mathrm{C}$ и 180 об./мин в течение 16-18 ч. По окончании инкубации бактериальные суспензии разводили в $10^{5}$ раз и с помощью автомата для посева easySpiral (Interscience; Франция) наносили по 10 мкл на чашки Петри с агаром LB без колистина и с агаром LB, содержащим 10 мг/л колистина. Инкубацию проводили при $37^{\circ} \mathrm{C}$ в течение 16-18ч. Подсчет KOE производили с помощью автоматического счетчика Scan 500 (Interscience; Франция). ИК рассчитывали как отношение числа кол-Р-KOE на чашке LB с колистином к числу кол-Ч-KOE на чашке LB без колистина. ИK < 1 означал сниженную конкурентоспособность кол-Р-изолята по сравнению с кол-Ч-изолятом. Эксперименты выполняли в трех повторах.

Статистическую обработку данных проводили с помощью программы IBM SPSS Statistics 20.0 (IBM SPSS Inc; США). Значения ПКР и числа колоний представляли в виде медианы $\left(\mathrm{P}_{25} ; \mathrm{P}_{75}\right)$, значения ИК выражали в виде среднего (стандартное отклонение). Различия ПКР оценивали при помощи теста Краскела-Уоллиса, парные сравнения проводили с использованием теста МаннаУитни. Различия считали значимыми при $p<0,05$.

\section{РЕЗУЛЬТАТЫ ИССЛЕДОВАНИЯ}

\section{Характеристика карба-Р-изолятов К. pneumoniae}

Bce 159 карба-Р-изолятов K. pneumoniae обладали МЛУфенотипом, т. е. были резистентными по меньшей мере к трем классам антимикробных препаратов. Все штаммы были устойчивы к цесалоспоринам 3-го и 4-го поколений, а также имели высокий уровень резистентности к ципрофрлоксацину (93\%), фосфомицину (90\%), нетилмицину (82\%), гентамицину (84\%), амикацину (50\%) и колистину (45\%). Большинство карба-Р-изолятов K. pneumoniae сохраняло чувствительность к тигециклину: только у $7 \%$ была отмечена резистентность.

По данным МЛСТ, исследованные карба-Р-изоляты были распределены между 18 сиквенс-типами, но большинство (86\%) относилось к пяти доминирующим сиквенс-типам: ST307 ( $n=46,29 \%)$, ST395 ( $n=40,25 \%)$, ST377 ( $n=17,10 \%)$, ST48 ( $n=17,10 \%)$ и ST23 $(n=16,10 \%)$.

\section{Механизмы устойчивости к колистину}

Резистентностью к колистину обладал 71 (45\%) карбаР-изолят K. pneumoniae, МПК колистина для которых варьировала от 4 до 1024 мг/л и более. Расшифровка молекулярных механизмов устойчивости к колистину была начата с поиска плазмидного гена $m c r-1$, который, по данным литературы, служит наиболее частой причиной резистентности [19]. Ни в одном из 71 кол-Р-изоляте K. pneumoniae ген mcr-1 обнаружен не был.

Далее мы исследовали структуру гена $\operatorname{mgrB}, \mathrm{c}$ повреждением которого может ассоциироваться устойчивость к колистину. Изменения mgrB были обнаружены у 23 (32\%) кол-Р-изолятов (табл. 1). В 4 (17\%) изолятах была выявлена делеция всего локуса $\mathrm{mgrB}$. У 13 (56\%) изолятов mgrB был поврежден вставочными элементами четырех различных типов (IS1A, IS1R, ISKpn14 и ISKpn26) из семейств IS-1 и IS-5, внедренными в разные позиции $m g r B$ (см. табл. 1). В гене $\operatorname{mgrB}$ у 6 (26\%) колР-изолятов был обнаружен новый мобильный элемент MITEKpn1, который охарактеризован в нашей недавней публикации [16].

Таким образом, 48 из 71 (68\%) кол-Р-изолятов K. pneumoniae содержали ген mgrB дикого типа, что требовало поиска других механизмов устойчивости к колистину. С этой целью во всех 48 кол-Р-изолятах, имевших $\mathrm{mgrB}$ дикого типа, мы проанализировали аминокислотные последовательности белков PmrA, PmrB, PhoP и PhoQ, участвующих в процессах модификации ЛПС, повреждение которых может вызывать устойчивость к колистину [10]. Значимые изменения PmrA и/или PmrB были выявлены у трех изолятов, которые принадлежали к трем разным сиквенс-типам (ST307, ST395, ST48) с МПК колистина в диапазоне от 128 до 1024 мг/л и более (см. табл. 1).

\section{Влияние устойчивости к колистину на бактериальный фитнес}

Кинетика роста кол-Р- и кол-Ч-изолятов K. pneumoniae в отсутствие колистина различалась незначимо, медианы ПКР составили 4,2 (3,9; 4,3) и 4,05 $(3,9 ; 4,6)$ ОП $_{600}$ за 1 ч соответственно ( $p=0,842$; табл. 2). Добавление 1 мг/л колистина резко снижало ПКР кол-Ч-изолятов до $1,9(0,95 ; 4,13)$ ОП концентрации колистина ожидаемо полностью подавляли рост чувствительных изолятов (см. табл. 2). Кол-Р-изоляты K. pneumoniae сохраняли обычную кинетику роста при содержании колистина 1 мг/л и демонстрировали ее значимое снижение в присутствии 4 и 16 мг/л колистина ( $p=0,016$ и $p<0,001$ соответственно). Почти полное угнетение роста кол-Р-изолятов обнаружено при добавлении колистина в концентрации 64 мг/л, когда ПКР составила 0,9 (0; 3,0) ОП 600 за 1 ч (см. табл. 2).

При сравнении ПКР кол-Р-изолятов с поврежденным mgrB и mgrB дикого типа (см. табл. 2) оказалось, что статус mgrB незначимо влиял на кинетику роста бактериальной популяции вне зависимости от концентрации колистина.

Затем мы провели исследование 26 кол-Ризолятов и рассчитали ИК в экспериментах по оценке конкурентоспособности относительно карба-Ч/кол-Ч-

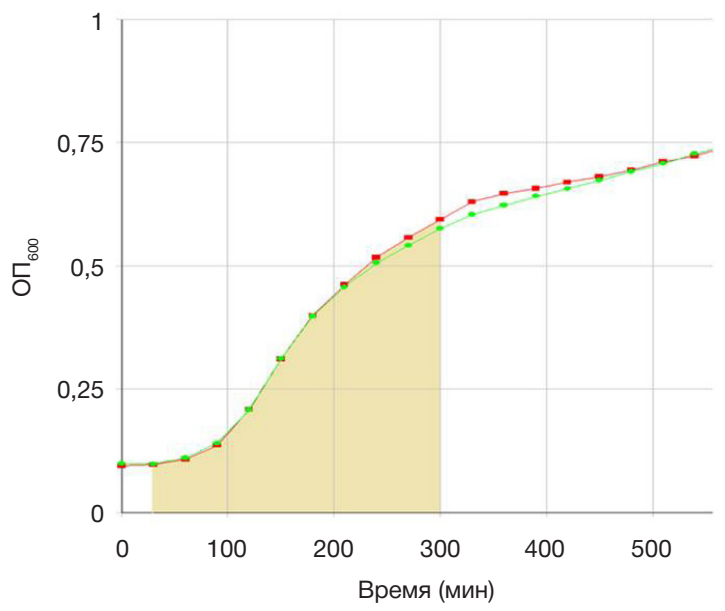

Рис. 1. Типичные кривые роста изолятов K. pneumoniae в среде без колистина. Заштрихованная область - площадь под кривой роста (ПКР). Красная линия - кривая роста кол-Ч-изолята; зеленая линия — кривая роста кол-Р-изолята 
Таблица 1. Генотипы, фенотип и механизмы устойчивости к колистину у карба-Р-изолятов K. pneumoniae $(n=26)$

\begin{tabular}{|c|c|c|c|}
\hline № изолята & ST & МПК колистина, мг/л & Статус $m g r B^{\text {a }}$ \\
\hline 69-77 & 23 & 128 & IS 1A, семейство IS-1 (+127/+128) \\
\hline 56-1790 & 307 & 64 & IS1R, семейство IS-1 (+36/+37) \\
\hline 68-66-1 & 48 & 16 & ISKpn14, семейство IS-1 (+141/+142) \\
\hline 58-2876 & 48 & 128 & ISKpn14, семейство IS-1 (+141/+142) \\
\hline $58-3431$ & 48 & 128 & ISKpn14, семейство IS-1 (+141/+142) \\
\hline $58-2966$ & 48 & 512 & ISKpn14, семейство IS-1 (+141/+142) \\
\hline 56-1678 & 48 & $\geq 1024$ & ISKpn14, семейство IS-1 (+141/+142) \\
\hline 56-1053 & 48 & $\geq 1024$ & ISKpn14, семейство IS-1 (+141/+142) \\
\hline 71-1375 & 307 & 512 & ISKpn14, семейство IS-1 (+141/+142) \\
\hline 76-2089 & 377 & 512 & ISKpn14, семейство IS-1 (+141/+142) \\
\hline $64-574$ & 307 & 256 & ISKpn26, семейство IS-5 (+74/+75) \\
\hline 4469 & 395 & 128 & ISKpn26, семейство IS-5 (+74/+75) \\
\hline 52-1659 & 395 & 256 & ISKpn26, семейство IS-5 (+74/+75) \\
\hline 58-1363 & 307 & 16 & MITEKpn1, семейство IS-5 (+74/+75) \\
\hline $55-148$ & 307 & 64 & MITEKpn1, семейство IS-5 (+74/+75) \\
\hline $56-566$ & 307 & 128 & MITEKpn1, семейство IS-5 (+74/+75) \\
\hline $58-1286$ & 307 & 128 & MITEKpn1, семейство IS-5 (+74/+75) \\
\hline $56-613$ & 307 & 512 & MITEKpn1, семейство IS-5 (+74/+75) \\
\hline $48-1594$ & 307 & $\geq 1024$ & MITEKpn1, семейство IS-5 (+74/+75) \\
\hline $78-296$ & 37 & 16 & $\Delta m g r B$ локуса \\
\hline 37262 & 147 & 64 & $\Delta m g r B$ локуса \\
\hline 29423 & 70 & 128 & $\Delta m g r B$ локуса \\
\hline $36-2246$ & 395 & 128 & $\Delta m g r B$ локуса \\
\hline $46-1574$ & 307 & 128 & Дикий тип ${ }^{6}$ \\
\hline 48-2246 & 395 & $\geq 1024$ & Дикий тип в \\
\hline $56-410$ & 48 & 128 & Дикий тип г \\
\hline
\end{tabular}

Примечание: ST — сиквенс-тип; МПК - минимальная подавляющая концентрация; а — в скобках указана нуклеотидная позиция встраивания вставочного элемента; ${ }^{6}$ - изменения PmrB (T157P); в — изменения PmrA (A141T) и PmrB (L213M, G256R); г — изменения PmrB (делеция 27-30 (QLIS)).

изолята K. pneumoniae при их совместном культивировании (рис. 2; см. табл. 2). Среднее значение ИК составило 0,15 (0,21), при этом у 25/26 (96\%) кол-Р-изолятов ИК был < 1 и варьировал от 0,01 до 0,53, а один изолят имел ИК = 1 . Изоляты с диким типом и повреждением mgrB обладали похожими ИК, которые составили 0,19 $(0,26)$ и 0,1 $(0,1)$ соответственно ( $p=0,283$; см. табл. 2). Таким образом, резистентность к колистину у подавляющего числа кол-Ризолятов K. pneumoniae была ассоциирована со снижением конкурентоспособности по отношению к карба-Ч/кол-Чизолятам K. pneumoniae, которое не зависело от статуса гена $\mathrm{mgrB}$.

Влияние устойчивости к колистину на бактериальный фитнес было дополнительно исследовано в карба-Р/кол-Ч и карба-Р/кол-Р парах K. pneumoniae, относившихся $\mathrm{K}$ одному сиквенс-типу. Для данных экспериментов были отобраны изоляты пяти наиболее распространенных (ST23, ST48, ST307, ST377 и ST395) и одного редкого (ST147) сиквенс-типов, среди которых в коллекции имелся минимум один кол-Ч-изолят (табл. 3). Конкурентоспособность всех кол-Р-изолятов ST48, ST147, ST307 и ST377 относительно кол-Ч-изолятов аналогичных сиквенс-типов была снижена, о чем свидетельствовал ИК < 1. Результаты исследования изолятов двух других сиквенс-типов, ST23 и ST395, не были так однозначны. Один кол-Р-изолят ST23 (ИК = 1,3) и два кол-Р-изолята ST395 (ИК $=1,87$ и ИК $=2,5)$ продемонстрировали повышенный фитнес относительно своих кол-Ч-аналогов (см. табл. 3).

\section{ОБСУЖДЕНИЕ РЕЗУЛЬТАТОВ}

Большинство карба-Р-изолятов K. pneumoniae в нашей коллекции относилось к пяти глобальным сиквенстипам, причем два генотипа, ST307 и ST395, суммарно составляли 54\%. По данным ряда авторов, ST307 ранее не входил в число доминирующих сиквенс-типов на территории нашей страны [20, 21], но в настоящее время становится одним из ведущих международных сиквенстипов высокого риска [7], что согласуется с полученными нами данными.

Существенная доля (45\%) исследованных нами карба-Р-изолятов была устойчива к колистину. По данным многоцентрового исследования «МАРАФОН" [2, 3], в большой выборке госпитальных K. pneumoniae распространенность кол-Р-изолятов была низкой, хотя и возросла с 4,5\% в 2012 г. до 7,9\% в 2014 г. Наши данные могут отражать общую тенденцию к повышению антибиотикорезистентности, которая затрагивает и устойчивость к колистину. Например, 15-летнее ретроспективное исследование в крупном госпитале в Афинах показало резкое увеличение доли кол-Ризолятов K. pneumoniae из гемокультур с 0\% в 2002 г. до 26,9\% в 2016 [22]. Вместе с тем высокая частота встречаемости кол-Р-штаммов в нашей коллекции могла быть связана с преобладанием изолятов, полученных в отделениях реанимации и интенсивной терапии, где, по данным Feretzakis и соавт. [23], доля кол-Р-изолятов 

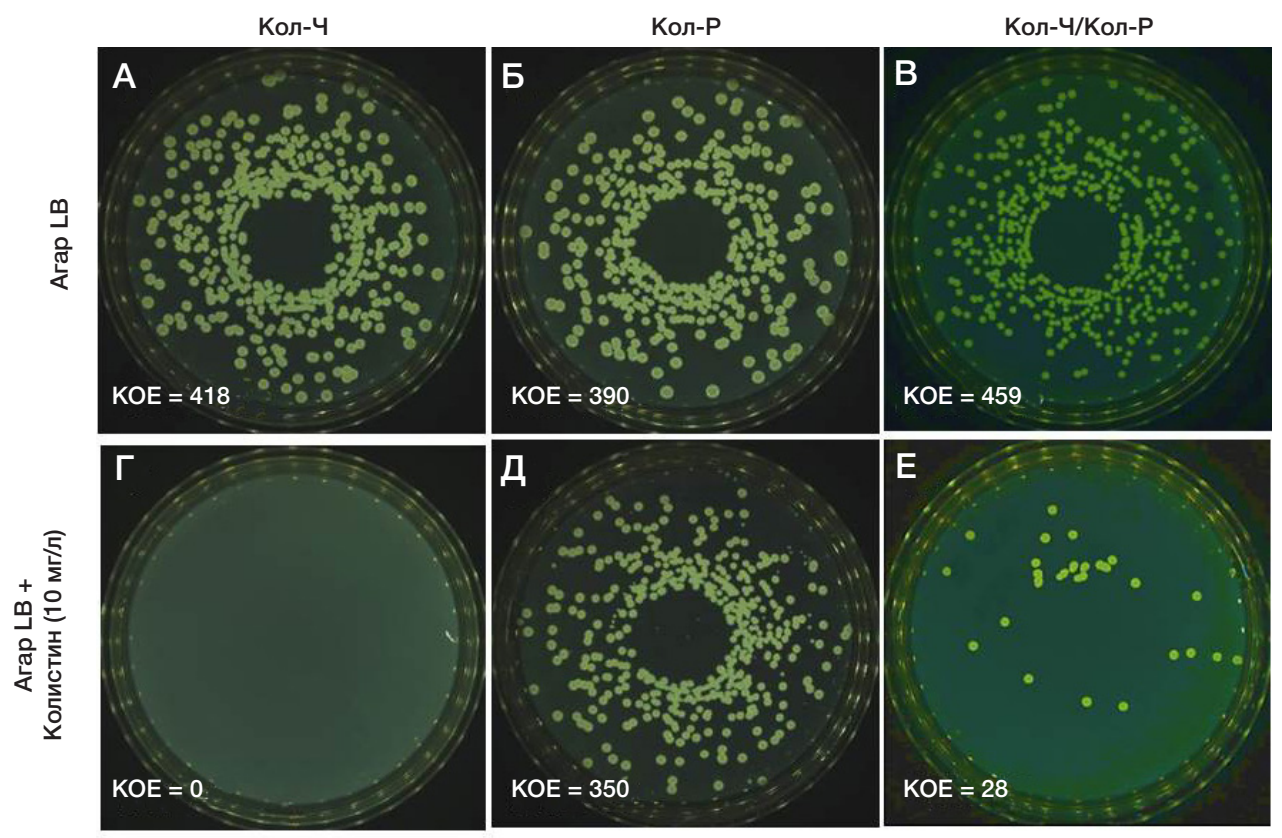

Рис. 2. Репрезентативный эксперимент по оценке конкурентоспособности колистинрезистентных К. рпеитопіае. Кол-Ч - колистинчувствительные; кол-Р - колистинрезистентные; кол-Ч /кол-Р - смесь колистинчувствительных и колистинрезистентных изолятов; КОЕ - колониеобразующие единицы. Фотографии чашек Петри демонстрируют характер роста кол-Ч-изолятов (А, Г), кол-Р-изолятов (Б, Д) и смеси кол-Р / кол-Ч-изолятов (В, Е) K. pneumoniae на агаре LB без колистина (A-B) и агаре LB с содержанием 10 мг/л колистина (Г-Е). Цифры указывают число КОЕ на каждой чашке. Индекс конкурентоспособности (ИК) рассчитан как число KOE на LB + колистин / (число KOE на LB - число KOE на LB + KOлистин), т. е. KOE «Е» / (KOE «B» - KOE «Е»)

K. pneumoniae может кратно превышать долю таковых в других отделениях (40 против 13,8\%). Кроме того, прямое сравнение исследований, в которых использованы различные способы тестирования устойчивости к колистину, может иметь известные трудности. Так, эпсилометрические Е-тесты могут давать высокую долю ошибочных результатов по сравнению с референсным методом микроразведений, препятствуя выявлению реальной частоты колистинрезистентности [9, 20].

Наличие устойчивости к колистину не влияло на кинетику роста в отсутствие антибиотика и не зависело от статуса гена $\mathrm{mgrB}$, что согласуется с результатами предыдущих исследований [24]. В противоположность этому, устойчивость к колистину у Acinetobacter baumannii и Pseudomonas aeruginosa сопровождается выраженными нарушениями динамики роста бактериальной популяции $[13,25]$, что может объяснять сравнительно высокую распространенность энтеробактерий с хромосомной устойчивостью к колистину по сравнению с кол-Р A. baumannii и $P$. aeruginosa.

В то же время подавляющее большинство кол-Р-изолятов демонстрировали снижение конкурентоспособности по сравнению с кол-Ч-изолятами K. pneumoniae, что характерно и для других видов бактерий, в частности A. baumannii [13] и P. aeruginosa [25]. Описано снижение бактериального фитнеса у кол-P K. pneumoniae, являющихся носителями гена $m c r-1$ [26].

Интересные результаты были получены в конкурентных экспериментах с кол-Р- и кол-Ч-изолятами K. pneumoniae одного сиквенс-типа, т. е. бактериями с очень схожим генотипом, но различающимися чувствительностью к колистину. Было исследовано шесть разных сиквенстипов, и большинство протестированных кол-Р-изолятов демонстрировали снижение ИК. В то же время у двух кол-

Таблица 2. Влияние устойчивости к колистину на бактериальный фитнес (кинетику роста и индекс конкуренции) карба-Р-изолятов К. рпеитопіае

\begin{tabular}{|c|c|c|c|c|c|c|c|}
\hline \multirow{3}{*}{ Изоляты } & \multirow{3}{*}{$\begin{array}{l}\text { МПК колистина, } \\
\text { мг/л; Ме }\left(\mathrm{P}_{25} ; \mathrm{P}_{75}\right)\end{array}$} & \multicolumn{5}{|c|}{ ПКР (ОП 600 за 1 ч), $\mathrm{Me}\left(\mathrm{P}_{25} ; \mathrm{P}_{75}\right)$} & \multirow{3}{*}{$\begin{array}{l}\text { ИК, среднеє } \\
\text { (СО) }\end{array}$} \\
\hline & & \multicolumn{5}{|c|}{ Концентрация колистина, мг/л } & \\
\hline & & 0 & 1 & 4 & 16 & 64 & \\
\hline Кол-Ч $(n=6)$ & $<1(<1 ;<1)$ & $4,05(3,9 ; 4,6)$ & $1,9(0,95 ; 4,13)$ & $0(0 ; 4,03)$ & $0(0 ; 0)$ & $0(0 ; 0)$ & $\mathrm{H} \Pi$ \\
\hline Кол-P $(n=32)$ & $256(128 ; 512)$ & $4,2(3,9 ; 4,3)^{\mathrm{a}}$ & $4,1(3,7 ; 4,2)^{6}$ & $3,9(3,2 ; 4,15)^{\mathrm{B}}$ & $3,3(2,2 ; 3,45) r$ & $0,9(0 ; 3)^{r}$ & $0,15(0,21)^{\mathrm{e}}$ \\
\hline \multicolumn{8}{|l|}{ Из них: } \\
\hline $\begin{array}{l}\text { mgrB, поврежденный } \\
(n=15)\end{array}$ & $256(128 ; 512)$ & $4,1(3,9 ; 4,2)$ & $4(3,9 ; 4,2)$ & $3,9(3,1 ; 4,1)$ & $3,4(0,9 ; 3,7)$ & $1,1(0 ; 3,3)$ & $0,1(0,1)^{*}$ \\
\hline $\begin{array}{l}\text { mgrB, дикий тип } \\
(n=17)\end{array}$ & $256(96 ; 512)$ & $4,3(3,85 ; 4,4)^{\text {म }}$ & $4,2(3,53 ; 4,25)^{\mathrm{A}}$ & $3,8(3,18 ; 4,25)^{\text {म }}$ & $3,25(2,75 ; 3,43)^{\text {म }}$ & $0,9(0 ; 3)^{\text {म }}$ & $0,19(0,26)^{3, n}$ \\
\hline
\end{tabular}

Примечание: МПК - минимальная подавляющая концентрация; ПКР - площадь под кривой роста; Ме - медиана; $\mathrm{P}_{25}$ и $\mathrm{P}_{75}$ - 25-й и 75-й перцентили; ИК - индекс конкуренции; СО - стандартное отклонение; кол-Ч — колистинчувствительные; кол-Р — колистинрезистентные; НП — не применимо; а $p=0,842$ при сравнении с ПКР кол-Ч-изолятов; ${ }^{6}-p=0,19$ при сравнении с ПКР кол-Р-изолятов при концентрации колистина 0 мг/л; ${ }^{\text {в }}-p=0,016$ при сравнении с ПКР кол-Р-изолятов при концентрации колистина 0 мг/л; г $-p<0,001$ при сравнении с ПКР кол-Р-изолятов при концентрации колистина О мг/л; ${ }^{\text {A }}-p>0,05$ при сравнении с ПКР кол-Р-изолятов с поврежденным $\operatorname{mgrB;}{ }^{e}-n=26 ;{ }^{*}-n=11 ;{ }^{3}-n=15 ;{ }^{n}-p=0,283$ при сравнении с ИК кол-Р-изолятов с поврежденным mgrB. 
Таблица 3. Индекс конкуренции кол-Р- и кол-Ч-изолятов карба-Р К. pneumoniae одинаковых сиквенс-типов

\begin{tabular}{|c|c|c|c|c|c|}
\hline \multicolumn{2}{|c|}{ Кол-Р-изоляты } & \multirow{2}{*}{ Механизм кол-Р } & \multicolumn{2}{|c|}{ Число КОЕ (СО) } & \multirow{2}{*}{ ИК (CO) } \\
\hline ST & № изолята & & Кол-Р (агар LB + колистин, 10 мг/л) & Кол-Ч + кол-Р (агар LB) & \\
\hline \multirow[t]{4}{*}{ ST23 } & 37261 & Неизвестный & 80 & 141 & 1,3 \\
\hline & 69-77 & Поврежденный mgrB & 39 & 168 & 0,3 \\
\hline & 37243 & Неизвестный & 25 & 112 & 0,29 \\
\hline & 37224 & Неизвестный & 5 & 114 & 0,05 \\
\hline \multicolumn{3}{|c|}{ Итого ST23: } & 37 (32) & $134(26)$ & $0,48(0,56)$ \\
\hline \multirow[t]{4}{*}{ ST395 } & 52-1659 & Поврежденный mgrB & 88 & 135 & 1,87 \\
\hline & $78-1127$ & Неизвестный & 3 & 138 & 0,02 \\
\hline & $59-397$ & Неизвестный & 110 & 153 & 2,5 \\
\hline & 4469 & Поврежденный mgrB & 17 & 141 & 0,14 \\
\hline \multicolumn{3}{|c|}{ Итого ST395: } & $55(53)$ & $142(8)$ & $1,1(1,24)$ \\
\hline \multirow[t]{3}{*}{ ST377 } & $76-1648$ & Неизвестный & 90 & 335 & 0,37 \\
\hline & $76-2053$ & Неизвестный & 38 & 282 & 0,16 \\
\hline & 76-2089 & Поврежденный mgrB & 79 & 232 & 0,52 \\
\hline \multicolumn{3}{|c|}{ Итого ST377: } & $69(27)$ & $283(52)$ & $0,35(0,18)$ \\
\hline \multirow[t]{3}{*}{ ST307 } & $64-574$ & Поврежденный $\mathrm{mgrB}$ & 33 & 287 & 0,13 \\
\hline & $56-566$ & Поврежденный mgrB & 68 & 210 & 0,48 \\
\hline & 71-1375 & Поврежденный $m g r B$ & 63 & 196 & 0,47 \\
\hline \multicolumn{3}{|c|}{ Итого ST307: } & $55(19)$ & $231(49)$ & $0,36(0,2)$ \\
\hline ST147 & $37-262$ & Поврежденный $\mathrm{mgrB}$ & 3 & 201 & 0,02 \\
\hline ST48 & 58-2966 & Поврежденный mgrB & 8 & 152 & 0,06 \\
\hline
\end{tabular}

Примечание: ИК - индекс конкуренции; СО — стандартное отклонение.

P-ST395-изолятов и одного кол-Р-ST23-изолята уровень конкурентоспособности оказался выше, чем у кол-Чизолятов аналогичных ST.

Это можно объяснить наличием в их геноме возможных компенсаторных мутаций, как было описано в случае с резистентностью к фторхинолонам и колистину у Escherichia coli [27] и A. baumannii [28]. Компенсаторные мутации в противовес мутациям, приводящим к резистентности, увеличивают бактериальный фитнес резистентных изолятов и тем самым способствуют распространению устойчивости даже в отсутствие селективного воздействия антибиотика [27, 28].

Таким образом, устойчивость к колистину широко распространена в популяции карба-Р-изолятов K. pneumoniae, выделенных у пациентов в г. Москве. Настораживающая эпидемиологическая ситуация в отношении кол-Р-бактерий требует проведения дальнейшего тщательного мониторинга.

\section{Литература}

1. Суворова М. П., Яковлев С. В., Белобородов В. Б., Басин Е. Е. Елисеева К. В., Ковеленов С. В. Распространенность и клиническое значение нозокомиальных инфекций в лечебных учреждениях России: исследование ЭРГИНИ. Антибиотики и химиотерапия. 2016; 61 (5-6): 32-42.

2. Сухорукова М. В., Эйдельштейн М. В., Склеенова Е. Ю., Иванчик Н. В., Микотина А. В., Дехнич А. В. и др. Антибиотикорезистентность нозокомиальных штаммов Enterobacteriaceae в стационарах России: результаты многоцентрового эпидемиологического исследования «МАРАФОН» 2013-2014. Клиническая микробиология и антимикробная химиотерапия. 2017; 19 (1): 49-56.

3. Сухорукова М. В., Эйдельштейн М. В., Склеенова Е. Ю.

\section{ВЫВОДь}

Среди сиквенс-типов карба-Р-изолятов K. pneumoniae в нашей коллекции лидируют ST307 и ST395, а ведущим механизмом устойчивости к колистину является изменение гена $m g r B$ различными вставочными элементами.

Изучение бактериального фитнеса кол-Р-изолятов K. pneumoniae позволило определить, что устойчивость К колистину не влияет на кинетику роста в его отсутствие и не зависит от статуса гена $\mathrm{mgrB}$; подавляющее большинство кол-Р-изолятов $K$. pneumoniae имеют сниженную конкурентоспособность по сравнению с кол-Ч-изолятами, однако в рамках одного сиквенс-типа встречаются колР-изоляты с повышенной конкурентоспособностью. Это определяет необходимость дальнейшего исследования бактериального фитнеса для понимания причин распространения резистентности к колистину среди энтеробактерий
Иванчик Н. В., Тимохова А. В., Дехнич А. В. и др. Антибиотикорезистентность нозокомиальных штаммов Enterobacteriaceae в стационарах России: результаты многоцентрового эпидемиологического исследования МАРАФОН в 2011-2012 гг. Клиническая микробиология и антимикробная химиотерапия. 2014; 16 (4): 254-65.

4. Lee CR, Lee JH, Park KS, Kim YB, Jeong BC, Lee SH. Global dissemination of carbapenemase-producing Klebsiella pneumoniae: Epidemiology, genetic context, treatment options, and detection methods. Front Microbiol. 2016; 7: 1-30.

5. Wyres KL, Holt KE. Klebsiella pneumoniae Population Genomics and Antimicrobial-Resistant Clones. Trends Microbiol. 2016; 24 (12): 944-56. 
6. Izdebski R, Baraniak A, Zabicka D, Machulska M, Urbanowicz $\mathrm{P}$, Fiett $\mathrm{J}$, et al. Enterobacteriaceae producing OXA-48-like carbapenemases in Poland, 2013-January 2017. J Antimicrob Chemother. 2018; 73 (3): 620-25.

7. Wyres KL, Hawkey J, Hetland MAK, Fostervold A, Wick RR, Judd LM, et al. Emergence and rapid global dissemination of CTX-M-15associated Klebsiella pneumoniae strain ST307. J Antimicrob Chemother. 2019; 74 (3): 577-81.

8. Ah YM, Kim AJ, Lee JY. Colistin resistance in Klebsiella pneumoniae. International Journal of Antimicrobial Agents. 2014; 44 (1): 8-15.

9. Rojas LJ, Salim M, Cober E, Richter SS, Perez F, Salata RA et al. Colistin Resistance in Carbapenem-Resistant Klebsiella pneumoniae: Laboratory Detection and Impact on Mortality. Clin Infect Dis. 2017; 64 (6): 711-8.

10. Poirel L, Aurelie J, Nordmann P. Polymyxins: Antibacterial Activity, Susceptibility Testing, and Resistance Mechanisms Encoded by Plasmids or Chromosomes. Clin Microbiol Rev. 2017; 30 (2): 557-96.

11. Guo B, Abdelraouf K, Ledesma KR, Nikolaou M, Tam VH. Predicting bacterial fitness cost associated with drug resistance. J Antimicrob Chemother. 2012; 67 (4): 928-32.

12. Ternent L, Dyson RJ, Krachler AM, Jabbari S. Bacterial fitness shapes the population dynamics of antibiotic-resistant and -susceptible bacteria in a model of combined antibiotic and antivirulence treatment. J Theor Biol. 2015; 372: 1-11.

13. Beceiro A, Moreno A, Fernandez N, Vallejo JA, Aranda J, Adler B, et al. Biological cost of different mechanisms of colistin resistance and their impact on virulence in Acinetobacter baumannii. Antimicrob Agents Chemother. 2014; 58 (1): 518-26.

14. Choi MJ, Ko KS. Loss of hypermucoviscosity and increased fitness cost in colistin-resistant Klebsiella pneumoniae sequence type 23 strains. Antimicrob Agents Chemother. 2015; 59 (11): 6763-73.

15. eucast.org [Internet]. European Committee on Antimicrobial Susceptibility Testing (EUCAST). Break- point tables for interpretation of MICs and zone diameters, version 8.0; c2018 [cited 2018 Dec 25]. Available from: http://www.eucast.org/ clinical_breakpoints/.

16. Shamina OV, Kryzhanovskaya OA, Lazareva AV, Alyabieva NM, Polikarpova SV, Karaseva OV, et al. Emergence of a ST307 clone carrying a novel insertion element MITEKpn1 in the mgrB gene among carbapenem-resistant Klebsiella pneumoniae from Moscow, Russia. Int J Antimicrob Agents. 2020; 55 (2): 105850.

17. Klebsiella pneumoniae MLST [база данных]. Доступно по ссылке: http://www.pasteur.fr/mlst/.

\section{References}

1. Suvorova MP, Yakovlev SV, Beloborodov VB, Basin EE, Eliseeva KV, Kovelenov SV. Rasprostranennost' i klinicheskoe znachenie nozokomial'nykh infektsiy v lechebnykh uchrezhdeniyakh Rossii: issledovanie ERGINI. Antibiotiki i khimioterapiya. 2016; 61 (5-6): 32-42. Russian.

2. Sukhorukova MV, Edelstein MV, Skleenova EY, Ivanchik NV, Mikotina AV, Dekhnich AV et al. Antimicrobial resistance of nosocomial Enterobacteriaceae isolates in Russia: results of multicenter epidemiological study "MARATHON" 2013-2014. CMAC. 2017; 19 (1): 49-56.

3. Sukhorukova MV, Edelstein MV, Skleenova EY, Ivanchik NV, Timokhova AV, Dekhnich AV et al. Antimicrobial resistance of nosocomial Enterobacteriaceae isolates in Russia: results of national multicenter surveillance study «MARATHON» 2011-2012. CMAC. 2014; 16 (4): 254-65.

4. Lee CR, Lee JH, Park KS, Kim YB, Jeong BC, Lee SH Global dissemination of carbapenemase-producing Klebsiella pneumoniae: Epidemiology, genetic context, treatment options, and detection methods. Front Microbiol. 2016; 7: 1-30.

5. Wyres KL, Holt KE. Klebsiella pneumoniae Population Genomics and Antimicrobial-Resistant Clones. Trends Microbiol. 2016; 24 (12): 944-56.

6. Izdebski R, Baraniak A, Zabicka D, Machulska M, Urbanowicz P,
18. ISfinder database [Internet] [cited 2018 Nov 18]. Available from: http://www-is.biotoul.fr/is.html.

19. Baron S, Hadjadj L, Rolain JM, Olaitan AO. Molecular mechanisms of polymyxin resistance: knowns and unknowns. Int $\mathrm{J}$ Antimicrob Agents. 2016; 48 (6): 583-91.

20. Шамина О. В., Крыжановская О. А., Лазарева А. В., Поликарпова С. В., Карасёва О. В., Чеботарь И. В. и др. Сравнение методов определения устойчивости К колистину у карбапенемрезистентных штаммов Klebsiella pneumoniae. Клиническая лабораторная диагностика. 2018; 63 (10): 646-50.

21. Агеевец В. А. Молекулярная характеристика продуцентов карбапенемаз семейства Enterobacteriaceae, выделенных в Санкт-Петербурге [диссертация]. Спб., 2016.

22. Tansarli GS, Papaparaskevas J, Balaska M, Samarkos $M$, Pantazatou A, Markogiannakis A, et al. Colistin resistance in carbapenemase-producing Klebsiella pneumoniae bloodstream isolates: Evolution over 15 years and temporal association with colistin use by time series analysis. Int J Antimicrob Agents. 2018; 52 (3): 397-403.

23. Feretzakis G, Loupelis E, Sakagianni A, Skarmoutsou N, Michelidou S, Velentza A, et al. A 2-year single-centre audit on antibiotic resistance of Pseudomonas aeruginosa, Acinetobacter baumannii and Klebsiella pneumoniae strains from an intensive care unit and other wards in a general public hospital in Greece. Antibiotics (Basel). 2019; 8 (2): 62.

24. Cannatelli A, Santos-Lopez A, Giani T, Gonzalez-Zorn B, Rossolini GM. Polymyxin resistance caused by mgrB inactivation is not associated with significant biological cost in Klebsiella pneumoniae. Antimicrob Agents Chemother. 2015; 59 (5): 2898900.

25. Moskowitz SM, Brannon MK, Dasgupta N, Pier M, Sgambati N, Miller AK, et al. PmrB mutations promote polymyxin resistance of Pseudomonas aeruginosa isolated from colistin-treated cystic fibrosis patients. Antimicrob Agents Chemother. 2012; 56 (2): 1019-30.

26. Nang SC, Morris FC, McDonald MJ, Han ML, Wang J, Strugnell $\mathrm{RA}$, et al. Fitness cost of mcr-1-mediated polymyxin resistance in Klebsiella pneumoniae. J Antimicrob Chemother. 2018; 73 (6): 1604-10.

27. Marcusson LL, Frimodt-Møller N, Hughes D. Interplay in the selection of fluoroquinolone resistance and bacterial fitness. PLoS Pathog. 2009; 5 (8): e1000541.

28. Mu X, Wang N, Li X, Shi K, Zhou Z, Yu Y, et al. The Effect of Colistin Resistance-Associated Mutations on the Fitness of Acinetobacter baumannii. Front Microbiol. 2016; 7: 1715.

Fiett $J$, et al. Enterobacteriaceae producing OXA-48-like carbapenemases in Poland, 2013-January 2017. J Antimicrob Chemother. 2018; 73 (3): 620-25.

7. Wyres KL, Hawkey J, Hetland MAK, Fostervold A, Wick RR, Judd LM, et al. Emergence and rapid global dissemination of CTX-M-15associated Klebsiella pneumoniae strain ST307. J Antimicrob Chemother. 2019; 74 (3): 577-81.

8. Ah YM, Kim AJ, Lee JY. Colistin resistance in Klebsiella pneumoniae. International Journal of Antimicrobial Agents. 2014; 44 (1): 8-15.

9. Rojas LJ, Salim M, Cober E, Richter SS, Perez F, Salata RA et al. Colistin Resistance in Carbapenem-Resistant Klebsiella pneumoniae: Laboratory Detection and Impact on Mortality. Clin Infect Dis. 2017; 64 (6): 711-8.

10. Poirel L, Aurelie J, Nordmann P. Polymyxins: Antibacterial Activity, Susceptibility Testing, and Resistance Mechanisms Encoded by Plasmids or Chromosomes. Clin Microbiol Rev. 2017; 30 (2): 557-96.

11. Guo B, Abdelraouf $K$, Ledesma KR, Nikolaou M, Tam VH. Predicting bacterial fitness cost associated with drug resistance. $J$ Antimicrob Chemother. 2012; 67 (4): 928-32.

12. Ternent L, Dyson RJ, Krachler AM, Jabbari S. Bacterial fitness shapes the population dynamics of antibiotic-resistant and -susceptible bacteria in a model of combined antibiotic and anti- 
virulence treatment. J Theor Biol. 2015; 372: 1-11.

13. Beceiro A, Moreno A, Fernandez N, Vallejo JA, Aranda J, Adler B, et al. Biological cost of different mechanisms of colistin resistance and their impact on virulence in Acinetobacter baumannii. Antimicrob Agents Chemother. 2014; 58 (1): 518-26.

14. Choi MJ, Ko KS. Loss of hypermucoviscosity and increased fitness cost in colistin-resistant Klebsiella pneumoniae sequence type 23 strains. Antimicrob Agents Chemother. 2015; 59 (11): 6763-73.

15. eucast.org [Internet]. European Committee on Antimicrobial Susceptibility Testing (EUCAST). Break- point tables for interpretation of MICs and zone diameters, version 8.0; c2018 [cited 2018 Dec 25]. Available from: http://www.eucast.org/ clinical_breakpoints/.

16. Shamina OV, Kryzhanovskaya OA, Lazareva AV, Alyabieva NM, Polikarpova SV, Karaseva OV, et al. Emergence of a ST307 clone carrying a novel insertion element MITEKpn1 in the mgrB gene among carbapenem-resistant Klebsiella pneumoniae from Moscow, Russia. Int J Antimicrob Agents. 2020; 55 (2): 105850.

17. Klebsiella pneumoniae MLST [baza dannyh]. Available from: http://www.pasteur.fr/mlst/. Russian.

18. ISfinder database [Internet] [cited 2018 Nov 18]. Available from: http://www-is.biotoul.fr/is.html.

19. Baron S, Hadjadj L, Rolain JM, Olaitan AO. Molecular mechanisms of polymyxin resistance: knowns and unknowns. Int J Antimicrob Agents. 2016; 48 (6): 583-91.

20. Shamina OV, Kryzhanovskaya OA, Lazareva AV, Polikarpova SV, Karaseva OV, Chebotar IV et al. The comparison of methods for determination of colistin susceptibility in carbapenem-resistant Klebsiella pneumoniae. Klin Lab Diagn. 2018; 63 (10): 646-50.

21. Ageevets VA. Molekulyarnaya kharakteristika produtsentov karbapenemaz semeystva Enterobacteriaceae, vydelennykh v Sankt-Peterburge [dissertatsiya]. Spb., 2016. Russian.
22. Tansarli GS, Papaparaskevas J, Balaska M, Samarkos M, Pantazatou A, Markogiannakis A, et al. Colistin resistance in carbapenemase-producing Klebsiella pneumoniae bloodstream isolates: Evolution over 15 years and temporal association with colistin use by time series analysis. Int J Antimicrob Agents. 2018; 52 (3): 397-403.

23. Feretzakis G, Loupelis E, Sakagianni A, Skarmoutsou N, Michelidou S, Velentza A, et al. A 2-year single-centre audit on antibiotic resistance of Pseudomonas aeruginosa, Acinetobacter baumannii and Klebsiella pneumoniae strains from an intensive care unit and other wards in a general public hospital in Greece. Antibiotics (Basel). 2019; 8 (2): 62.

24. Cannatelli A, Santos-Lopez A, Giani T, Gonzalez-Zorn B, Rossolini GM. Polymyxin resistance caused by mgrB inactivation is not associated with significant biological cost in Klebsiella pneumoniae. Antimicrob Agents Chemother. 2015; 59 (5): 2898900.

25. Moskowitz SM, Brannon MK, Dasgupta N, Pier M, Sgambati N, Miller AK, et al. PmrB mutations promote polymyxin resistance of Pseudomonas aeruginosa isolated from colistin-treated cystic fibrosis patients. Antimicrob Agents Chemother. 2012; 56 (2): 1019-30.

26. Nang SC, Morris FC, McDonald MJ, Han ML, Wang J, Strugnell RA, et al. Fitness cost of mcr-1-mediated polymyxin resistance in Klebsiella pneumoniae. J Antimicrob Chemother. 2018; 73 (6): 1604-10.

27. Marcusson LL, Frimodt-Møller N, Hughes D. Interplay in the selection of fluoroquinolone resistance and bacterial fitness. PLoS Pathog. 2009; 5 (8): e1000541.

28. MuX, Wang N, LiX, Shi K, Zhou Z, Yu Y, et al. The Effect of Colistin Resistance-Associated Mutations on the Fitness of Acinetobacter baumannii. Front Microbiol. 2016; 7: 1715. 